\title{
The Impact of Outcrossing on Yields of 'Hass' Avocado
}

\author{
Lauren C. Garner ${ }^{1,3}$, Vanessa E.T.M. Ashworth², Michael T. Clegg' ${ }^{2}$, and Carol J. Lovatt \\ Department of Botany and Plant Sciences, University of California, Riverside, CA 92521-0124
}

\begin{abstract}
AdDitional INDEX wORDs. alternate bearing, bloom overlap, microsatellites, Persea americana
Abstract. 'Hass' avocado (Persea americana Mill.) is characterized by excessive flower and fruit abscission, resulting in extremely low fruit set. Low outcrossing rates might be a factor contributing to low yields. It is hypothesized that self-fertilized flowers and resulting fruit abscise at a much higher rate than fruit that are the product of outcrossing. However, significant relationships between outcrossing rates and yields have only been established in a few avocado studies. The objective of this research was to investigate the importance of outcrossing to yield in a commercial 'Hass' orchard containing 'Bacon', an effective pollinizer of 'Hass'. Microsatellite markers were used to determine the rate of outcrossing of fruit persisting to harvest on 'Hass' trees. Experiments were conducted during sequential on- and off-crop years. During both years, outcrossing rates were not related to yield or alternate bearing. These results indicate that outcrossing was not the primary factor affecting flower and fruit persistence and ultimately yield in this orchard for the two sequential years of this research.
\end{abstract}

Avocado and many other subtropical fruit tree crops are characterized by excessive flower and fruit abscission. Thousands of avocado flowers and immature fruit abscise in a single season (Cameron et al., 1952; Garner and Lovatt, 2008; Inoue and Takahashi, 1990; Lahav and Zamet, 1975; Slabbert, 1981), resulting in extremely low fruit set $(<0.1 \%)$, even in healthy, well-managed orchards (Whiley and Schaffer, 1994). Outcrossing might be a key factor in the retention of avocado flowers and fruit. In a series of papers from the laboratories of Degani and Gazit (Degani et al., 1986, 1989, 1990, 1997), isozyme analysis of avocado seeds demonstrated that fruit that were the product of self-fertilization abscised at a much higher rate than those that were the product of outcrossing. Although the selective retention of fruit that were the product of outcrossing was highly significant and well documented, significant relationships between outcrossing rates and yields were only established in a few of the Israeli studies and were often cultivar dependent (Degani et al., 1989, 1990, 1997). Under California growing conditions, correlations between outcrossing rates and yields of 'Hass', the current industry standard worldwide, were weak $\left[r^{2}=0.50, P=0.03\right.$ (Kobayashi et al., 2000); $r^{2}=0.11, P=0.004$ (Vrecenar-Gadus and Ellstrand, 1985)] or nonsignificant $\left[r^{2}=0.31, P=0.11\right.$ and $r^{2}=0.11, P=$ 0.67 (Kobayashi et al., 2000)]. As few published studies regarding the relationship between outcrossing rates and yields

\footnotetext{
Received for publication 7 Apr. 2008. Accepted for publication 27 May 2008. This research was supported in part by the Citrus Research Center and Agricultural Experiment Station of the University of California, Riverside. L.C.G. acknowledges the support of the University of California, Riverside. This paper represents a portion of the dissertation submitted by L.C.G. in partial fulfillment of requirements for a $\mathrm{PhD}$ in Botany at the University of California, Riverside.

We thank Rick Shade (Shade Farm Management, Carpinteria, CA) for use of the orchard and assistance with harvests and Marilyn Kobayashi for her assistance with the DNA extraction protocol.

${ }^{1}$ Current address: Horticulture and Crop Science Department, CA Polytechnic State University, San Luis Obispo, CA 93407.

${ }^{2}$ Current address: Department of Ecology and Evolutionary Biology, University of California, Irvine, CA 92697.

${ }^{3}$ Corresponding author. E-mail: lgarner@calpoly.edu.
}

have been conducted in California, additional investigations are needed.

For outcrossing to occur, bloom of pollinizers must overlap with that of 'Hass'. Researchers have compared the bloom periods of various avocado cultivars with that of 'Hass' in many growing regions, although not necessarily for the purpose of determining an effective pollinizer cultivar (Davenport, 1982; Demirkol, 2002; Garner, 2004; Loupassaki et al., 1995; Winslow and Enderud, 1955). 'Bacon' has significant bloom overlap with 'Hass' (Garner, 2004; Winslow and Enderud, 1955 ) and is a successful pollinizer of 'Hass' (Kobayashi et al., 2000; Vrecenar-Gadus and Ellstrand, 1985) under a range of California growing conditions.

A common phenomenon affecting avocado production worldwide is alternate bearing, seasonal cycles of high and low yields. Although the physiological basis of this mechanism in avocado remains a matter of contention (reviewed in Bower et al., 1990), these cycles might continue because of the effects of fruit set on the production of vegetative flushes bearing the following season's floral buds. Therefore, any technique that affects fruit persistence might also affect the degree of alternate bearing.

Given the conflicting results regarding the importance of outcrossing to 'Hass' yield and the limited number of studies conducted in California, the objective of this research was to quantify outcrossing in a commercially bearing 'Hass' orchard and to determine its contribution to yield and effect on alternative bearing.

\section{Materials and Methods}

Field CONDITIONS. The research was conducted using commercially bearing 6-year-old 'Hass' avocado trees on Mexicanrace rootstocks in an orchard in Carpinteria, CA (lat. $34^{\circ} \mathrm{N}$ ). This coastal site was temperate, although air temperatures and precipitation were significantly higher during the on-crop bloom than the off-crop bloom (Garner, 2004). Data trees were of uniform health, size, and vigor, and were subject to the same standard cultural practices as the remaining orchard trees. Five 'Bacon' trees were within the otherwise solid 'Hass' planting. 
Additionally, a 'Topa Topa' tree and one rogue Mexican-race tree were directly adjacent to the orchard. Thus, only three pollinizer cultivars were available to pollinate the 'Hass' trees, as no other cultivars were known to be present within a radius of $\approx 3 \mathrm{~km}$. All 'Hass' study trees were within $69 \mathrm{~m}$ of at least one pollinizer tree.

OUtCrossing RATES OF FRUIT PERSISTING TO HARVEST. Microsatellites, DNA sequences composed of tandem nucleotide repeats, are useful as genetic markers for avocado because microsatellites are polymorphic, which allows closely related individuals to be distinguished from one another, and their alleles are characterized by codominant Mendelian inheritance (Ashworth et al., 2004). During the harvests of an on- and offcrop year, up to 25 fruit were collected randomly from each of 10 data trees. When fewer than 25 fruit per tree were available, all harvested fruit were used. Fruit were refrigerated until embryo DNA extraction. In the off-crop year, sample sizes for two trees were too low ( $\leq 5$ fruit) to be included in statistical analyses of outcrossing rates. A total of 434 fruit was collected, with 361 embryo DNA samples suitable for final statistical analyses. DNA concentrations from the embryos of the remaining 73 fruit were too low to achieve reliable polymerase chain reaction (PCR) amplification.

DNA was extracted from avocado leaves for identification of suitable primer loci and from embryos as described in Kobayashi et al. (2000). DNA fragments were amplified with the primer AVO102 using a PCR protocol modified from Ashworth et al. (2004). The $10-\mu \mathrm{L}$ reaction mixture included 0.5 to $1.5 \mu \mathrm{L}$ of embryo DNA, 1.0 $\mu \mathrm{L}$ of PCR buffer (Qiagen, Valencia, CA), $1.35 \mu \mathrm{L}$ of dNTPs (1.25 mm; Sigma-Aldrich, St. Louis), $0.5 \mu \mathrm{L}$ of $\mathrm{MgCl}_{2}$ (25 mm; Qiagen), $1.5 \mu \mathrm{L}$ of unlabelled reverse primer (1.5 $\mu \mathrm{M}$; Sigma-Genosys, The Woodlands, TX), and $1.5 \mu \mathrm{L}$ of fluorescence-labeled forward primer $(1.5 \mu \mathrm{M})$ [primer (SigmaGenosys); fluorescent dye, NED (Perkin Elmer-Applied Biosystems, Foster City, CA); and $0.08 \mu \mathrm{L}$ Taq polymerase (Qiagen)]. Reactions were performed on a thermocycler (PTC-100TM programmable thermal controller; MJ Research, Watertown, MA) with the following settings: $5 \mathrm{~min}$ at $95{ }^{\circ} \mathrm{C}$; 32 cycles of denaturing at $95{ }^{\circ} \mathrm{C}$ for $1 \mathrm{~min}$, annealing at $58^{\circ} \mathrm{C}$ for $1 \mathrm{~min}$ and $72^{\circ} \mathrm{C}$ for $1 \mathrm{~min}$ with a final extension of $5 \mathrm{~min}$ at $72{ }^{\circ} \mathrm{C}$. Labeled PCR products were visualized and fragment sizes were calculated using an ABI 377 Automated DNA Sequencer and ABI GeneScan software (Perkin Elmer-Applied Biosystems) as described in Ashworth et al. (2004).

Numerous steps were taken to ensure the accurate identification of alleles. Each gel included control lanes of leaf DNA extracted from each pollinizer cultivar and 'Hass'. Any lanes that could not be clearly read were considered "failures" and samples were rerun using the same PCR and fragment visualization protocols described above. Furthermore, samples were not included in the analysis if band strength fell below 100 relative fluorescence units. Final fragment identification required that gel images and fragment size calculations generated by ABI GeneScan software be compared to rule out any incorrectly identified peaks.

To determine relationships between outcrossing and yield, data trees were harvested by a professional picking crew in October of each year. Total fruit mass harvested per tree and the total mass of 100 randomly collected fruit were determined and used to estimate the total number of fruit per tree. To express the degree of alternate bearing, the alternate bearing index (ABI) was calculated for the 2-year period using the equation:

$$
\mathrm{ABI}=\mid \text { yield }_{\text {year1 }}-\text { yield }_{\text {year2 }} \mid /\left(\text { yield }_{\text {year1 }}+\text { yield }_{\text {year } 2}\right)
$$

in which yield was defined as total kilograms of fruit per tree. $\mathrm{ABI}$ ranges from 0 (no alternate bearing) to 1 (complete alternate bearing).

Statistical anAlysis. Mean comparisons were conducted using two-tailed Student's $t$ tests at $P \leq 0.05$ or analysis of variance and Tukey's Studentized range test with a family error rate of $P \leq 0.05$. Regression analyses were conducted using the least squares method for the general linear model. Standard transformations and linear, quadratic, and cubic models were tested, and residual plots and $t$ tests of higher order terms were used to determine the most appropriate fit for each data set. Percent data were normally distributed and, therefore, were not transformed before analyses. Significant linear regressions were tested further to determine if outliers distorted the regression lines significantly using a method described by Neter et al. (1990). If regression analyses were not significant $(P>0.05)$ upon removal of the outlier, the relationship was described as not significant. The above-described analyses were conducted using Minitab statistical analysis program (Student Edition; Minitab, State College, PA).

\section{Results}

Microsatellite analysis using the AVO102 locus enabled the unambiguous distinction between embryos that were the product of self-fertilization and those that were the product of outcrossing. However, the determination of the pollen parent of embryos that were the product of outcrossing was not always possible due to a common allele $(W)$ among the potential donors ['Bacon', 'Topa Topa', and a rogue Mexican-race tree (Table 1)]. Donor trees provided significant bloom overlap, with 'Bacon' bloom occurring contemporaneously with 'Hass' during $84 \%$ and $80 \%$ of 'Hass' bloom days during the onand off-crop years, respectively (Garner, 2004). Despite this, fruit that were the product of self-fertilization made up the majority $(>85 \%)$ of fruit persisting to harvest in both crop years (Table 2). Outcrossing rates for the on- and off-crop years were not significantly different $(P>0.05$; Table 3$)$. Outcrossing rates were not related to the number or kilograms of fruit harvested for either crop year (Table 3 ) or for both crop years combined ( $P>0.05$ and $r^{2}<0.01$ for number and kilograms harvested). For example, in the on-year, Tree $\mathrm{F}$ had an outcrossing rate of $60 \%$ and a yield of 370 fruit, whereas Tree $\mathrm{G}$ had an outcrossing rate of $0 \%$ and a yield of 379 fruit. Additionally, outcrossing rates of $0 \%$ occurred during both years but yields of such trees

Table 1. Fragment sizes of PCR products (for microsatellite loci of avocado cultivar leaf tissue) amplified by primer pair AVO. $102 \mathrm{~F}^{\mathrm{z}}$ and AVO.102R $\mathrm{R}^{\mathrm{y}}$ (modified from Ashworth et al., 2004).

\begin{tabular}{lll}
\hline Avocado cultivar & \multicolumn{2}{c}{ Fragment size $(\mathrm{bp})$} \\
\hline Hass & $153(X)^{\mathrm{x}}$ & $200(Z)$ \\
Bacon & $158(W)$ & $160(Y)$ \\
Topa Topa & $158(W)$ & $197(V)$ \\
Rogue & $158(W)^{\mathrm{w}}$ &
\end{tabular}

$\overline{{ }^{z} \text { Forward primer sequence }\left(5^{\prime}-3^{\prime}\right) \text { : TTC GCC TTA TCA GCG TTA G. }}$ ${ }^{y}$ Reverse primer sequence $\left(5^{\prime}-3^{\prime}\right)$ : TCT TGG AAA GCC CTA CTC C. ${ }^{x}$ Allele labels.

${ }^{\text {wT }}$ The rogue cultivar, a Mexican-race tree, was homozygous for $W$. 
Table 2. Incidence of microsatellite genotypes for embryo DNA from avocado fruit collected for on- and off-crop harvests.

\begin{tabular}{|c|c|c|c|c|c|c|c|c|c|c|c|c|c|c|c|c|c|c|c|c|}
\hline \multirow{4}{*}{$\begin{array}{l}\text { Embryo } \\
\text { genotype }\end{array}$} & \multicolumn{20}{|c|}{ 'Hass' trees } \\
\hline & \multicolumn{2}{|c|}{ A } & \multicolumn{2}{|c|}{ B } & \multicolumn{2}{|c|}{$\mathrm{C}$} & \multicolumn{2}{|c|}{$\mathrm{D}$} & \multicolumn{2}{|c|}{ E } & \multicolumn{2}{|c|}{$\mathrm{F}$} & \multicolumn{2}{|c|}{ G } & \multicolumn{2}{|c|}{$\mathrm{H}$} & \multicolumn{2}{|c|}{ I } & \multicolumn{2}{|c|}{$\mathrm{J}$} \\
\hline & $\overline{\mathrm{On}}$ & Off & $\overline{\mathrm{On}}$ & Off & $\overline{\mathrm{On}}$ & Off & $\overline{\mathrm{On}}$ & Off & $\overline{\mathrm{On}}$ & Off & $\overline{\mathrm{On}}$ & Off & $\overline{\mathrm{On}}$ & Off & $\overline{\mathrm{On}}$ & Off & $\overline{\mathrm{On}}$ & Off & $\overline{\mathrm{On}}$ & Off \\
\hline & \multicolumn{20}{|c|}{-------------------------------------------- Incidence of genotype (no.)----- } \\
\hline$Z X$ & 9 & 6 & 11 & 10 & 10 & 1 & 14 & 12 & 12 & 12 & 2 & 1 & 9 & 0 & 10 & 4 & 10 & 4 & 7 & 10 \\
\hline$Z Z$ & 5 & 6 & 6 & 4 & 5 & 3 & 5 & 5 & 3 & 6 & 2 & 3 & 6 & 0 & 5 & 5 & 5 & 2 & 7 & 10 \\
\hline$X X$ & 5 & 8 & 3 & 4 & 5 & 1 & 2 & 4 & 4 & 3 & 2 & 3 & 4 & 0 & 4 & 10 & 3 & 2 & 7 & 3 \\
\hline$Z W$ & 0 & 0 & 0 & 0 & 0 & 0 & 0 & 1 & 0 & 0 & 1 & 4 & 0 & 0 & 0 & 0 & 1 & 0 & 0 & 0 \\
\hline$Z V$ & 0 & 0 & 0 & 0 & 0 & 0 & 0 & 0 & 0 & 0 & 0 & 0 & 0 & 0 & 0 & 0 & 0 & 0 & 0 & 0 \\
\hline$Z Y$ & 1 & 0 & 0 & 2 & 0 & 0 & 0 & 0 & 1 & 0 & 3 & 6 & 0 & 0 & 0 & 1 & 1 & 1 & 0 & 0 \\
\hline$X Y$ & 0 & 0 & 0 & 1 & 0 & 0 & 0 & 1 & 0 & 0 & 2 & 3 & 0 & 0 & 1 & 0 & 0 & 0 & 0 & 0 \\
\hline$X W$ & 0 & 1 & 0 & 0 & 0 & 0 & 0 & 0 & 0 & 0 & 3 & 2 & 0 & 0 & 0 & 0 & 0 & 0 & 0 & 0 \\
\hline$X V$ & 0 & 0 & 0 & 0 & 0 & 0 & 0 & 0 & 0 & 0 & 0 & 0 & 0 & 0 & 0 & 0 & 0 & 0 & 0 & 0 \\
\hline
\end{tabular}

ranged from 161 to 379 fruit per tree during the on-crop year and from 46 to 79 fruit per tree during the off-crop year (Table 3). The degree of alternate bearing was not significantly correlated with outcrossing rate (Table 3). Furthermore, high rates of outcrossing did not mitigate alternate bearing. For example, Tree $\mathrm{F}$ had consistently high outcrossing rates $(60 \%$ and $68 \%$ for the on- and off-crop years, respectively) and a high ABI (0.82). Thus, outcrossing ultimately had no effect on fruit persistence, final yield, or alternate bearing.

Tree F, which was directly adjacent to a 'Bacon' tree, had outcrossing rates significantly higher than the other study trees (family error rate, $P \leq 0.05$ ) during both crop years. Based on the method described in Neter et al. (1990), these outliers were removed and the regression analyses were conducted based on the nine remaining data trees. Outcrossing rates and distance to the nearest or second nearest pollinizer tree were not significantly related $\left(r^{2}=0.002-0.27, P=0.26-0.68\right.$; Table 4$)$.

Table 3. Relationships between outcrossing rate and avocado yield and alternate bearing index (ABI) during on- and off-crop years.

\begin{tabular}{|c|c|c|c|c|c|c|c|}
\hline \multirow{3}{*}{$\begin{array}{l}\text { 'Hass' } \\
\text { trees }\end{array}$} & \multirow{2}{*}{\multicolumn{2}{|c|}{$\begin{array}{c}\text { Outcrossing } \\
(\%)\end{array}$}} & \multicolumn{4}{|c|}{ Yield per tree } & \multirow[b]{3}{*}{$\mathrm{ABI}$} \\
\hline & & & \multicolumn{2}{|c|}{ Total mass $(\mathrm{kg})$} & \multicolumn{2}{|c|}{ Total fruit (no.) } & \\
\hline & On & Off & On & Off & On & Off & \\
\hline$\overline{\mathrm{A}}$ & 5 & 5 & 48.50 & 16.75 & 176 & 69 & $\overline{0.49}$ \\
\hline B & 0 & 14 & 53.22 & 11.40 & 225 & 48 & 0.65 \\
\hline $\mathrm{C}$ & 0 & $-^{z}$ & 75.16 & 1.50 & 369 & 7 & 0.96 \\
\hline $\mathrm{D}$ & 0 & 9 & 42.37 & 25.30 & 161 & 103 & 0.25 \\
\hline $\mathrm{E}$ & 5 & 0 & 62.81 & 10.00 & 239 & 46 & 0.73 \\
\hline $\mathrm{F}$ & 60 & 68 & 98.54 & 9.50 & 370 & 37 & 0.82 \\
\hline G & 0 & - & 82.00 & 0.90 & 379 & 3 & 0.98 \\
\hline $\mathrm{H}$ & 5 & 5 & 33.28 & 34.05 & 128 & 139 & 0.01 \\
\hline I & 10 & 11 & 110.94 & 2.85 & 608 & 12 & 0.95 \\
\hline $\mathrm{J}$ & 0 & 0 & 63.66 & 16.50 & 324 & 79 & 0.59 \\
\hline$P$ & \multirow{2}{*}{\multicolumn{2}{|c|}{$0.18^{\mathrm{y}}$}} & 0.14 & 0.48 & 0.50 & 0.40 & 0.35 \\
\hline$r^{2}$ & & & 0.25 & 0.09 & 0.06 & 0.12 & 0.14 \\
\hline
\end{tabular}

${ }^{\mathrm{z}}$ Data not included in analyses due to low fruit number in the off-crop year.

yProbability value for paired $t$ test comparison of yearly outcrossing rates and $P$ values for regression analyses between outcrossing rates and yield per crop year or mean outcrossing rate and ABI.

\section{Discussion}

Significant relationships between outcrossing and yield have been documented in Israel for several avocado cultivars, including 'Hass'(Degani et al., 1989, 1990, 1997). A progress report from a current study in Oxnard, CA, suggests that the presence of pollinizers might increase yield of neighboring 'Hass' trees (Arpaia et al., 2005). In contrast, outcrossing was not related or was only weakly related to yield in previous complete studies in California 'Hass' orchards (Kobayashi et al., 2000; Vrecenar-Gadus and Ellstrand, 1985). In the research reported herein, yield of 'Hass' avocado was not related to outcrossing.

In all previous research, the outcrossing rate of individual 'Hass' avocado trees varied over a wide range within an orchard and between studies (Degani et al., 1989; Kobayashi et al., 2000; Vrecenar-Gadus and Ellstrand, 1985). In a study conducted in Israel, Degani et al. (1989) reported an estimated rate of outcrossing of mature 'Hass' fruit on individual trees ranging from $\approx 20 \%$ to $100 \%$ and $0 \%$ to $70 \%$ with the pollinizers 'Ettinger' and 'Fuerte', respectively. Vrecenar-Gadus and Ellstrand (1985) reported mean outcrossing rates of $42.2 \%$ and $89.6 \%$ in two California 'Hass' orchards. Outcrossing rates of 'Hass' ranging from $6.6 \%$ to $100 \%$ were reported by Kobayashi et al. (2000) for seven California 'Hass' orchards, with an overall mean outcrossing rate of $31.4 \%$. In the current research, therefore, the range of outcrossing rates for individual trees of $0 \%$ to $68 \%$ (mean $=11 \% \pm 5 \%$ ) was consistent with those reported in previous studies. Consistent with such studies, the data reported herein further demonstrate that substantial 'Hass' yields are attainable in California orchards with high rates of self pollination.

There are numerous factors that could limit outcrossing rates and the potential contribution of outcrossing to fruit persistence and 'Hass' yield, including pollinizer and 'Hass' bloom overlap, weather conditions, pollinizer effectiveness, and the distance of 'Hass' trees to the nearest pollinizer.

The timing of bloom overlap between cultivars has not been reported in previous studies regarding outcrossing rates of 'Hass' with pollinizers. However, Degani et al. (1997) reported 
Table 4. Relationship between outcrossing rates (\%) in an on- and off-crop year and distance (m) between 'Hass' avocado study trees (A-J) and pollinizer trees.

\begin{tabular}{|c|c|c|c|c|c|c|c|c|c|c|}
\hline \multirow[b]{5}{*}{ Pollinizer tree } & \multicolumn{10}{|c|}{ 'Hass' trees } \\
\hline & A & B & $\mathrm{C}$ & $\mathrm{D}$ & $\mathrm{E}$ & $\mathrm{F}$ & G & $\mathrm{H}$ & I & $\mathrm{J}$ \\
\hline & $\begin{array}{ll}\text { On } & \text { Off }\end{array}$ & $\overline{\text { On } \quad \text { Off }}$ & $\overline{\text { On } \quad \text { Off }}$ & $\overline{\text { On } \quad \text { Off }}$ & $\overline{\text { On } \quad \text { Off }}$ & $\overline{\text { On } \quad \text { Off }}$ & $\overline{\text { On } \quad \text { Off }}$ & $\overline{\text { On } \quad \text { Off }}$ & $\overline{\text { On } \quad \text { Off }}$ & $\begin{array}{ll}\text { On } & \text { Off }\end{array}$ \\
\hline & 5 & 14 & $-z$ & 0 & 0 & 60 & - & 5 & 10 & 0 \\
\hline & & & & & ---- Distar & e (m) - - & & & & \\
\hline Bacon 1 & $35.21^{y}$ & 25.52 & 40.59 & 41.73 & 25.52 & 05.82 & 20.45 & 31.42 & 39.91 & 68.62 \\
\hline Bacon 2 & 60.37 & 62.36 & 65.12 & 70.14 & 51.54 & 55.24 & 73.61 & 84.60 & 43.77 & 16.57 \\
\hline Bacon 3 & 57.53 & 57.05 & 57.56 & 52.12 & 68.24 & 61.17 & 51.48 & 43.35 & 78.29 & 125.52 \\
\hline Bacon 4 & 65.89 & 68.22 & 68.09 & 73.68 & 57.63 & 76.51 & 96.34 & 106.04 & 47.21 & 23.55 \\
\hline Bacon 5 & 201.69 & 202.71 & 205.48 & 210.95 & 191.64 & 195.22 & 212.00 & 223.20 & 180.36 & 129.83 \\
\hline Тора Тора & 59.12 & 62.61 & 57.09 & 51.60 & 74.73 & 73.06 & 68.74 & 62.88 & 79.47 & 129.99 \\
\hline Rogue & 293.52 & 294.24 & 296.09 & 301.69 & 283.09 & 296.64 & 315.10 & 326.13 & 274.55 & 226.44 \\
\hline
\end{tabular}

${ }^{\mathrm{z}}$ Data not included in analyses due to low fruit number in the off-crop year.

'Bold numbers indicate the shortest distance between each 'Hass' and a pollinizer tree.

a range of outcrossing rates from $3 \%$ to $85 \%$ for 'Ettinger' after a bloom overlap of $\approx 2$ to 3 weeks with 'Ardith' trees. During the research reported herein, the combined bloom period of 'Topa Topa' and 'Bacon' overlapped with 'Hass' bloom for 164 and $108 \mathrm{~d}$ during the off- and on-crop years, respectively, with 'Bacon' bloom overlapping with more than $80 \%$ of 'Hass' bloom during both crop years (Garner, 2004). Thus, pollinizer and 'Hass' bloom overlap occurred throughout the majority of the bloom period of both crop years, demonstrating that bloom overlap was not a limiting factor to outcrossing.

Weather conditions might also affect outcrossing rates. Certain cultivars, including Hass, open as functionally female in the morning of the first day and as functionally male in the afternoon of the second day under typical environmental conditions (Stout, 1923). Cool day and night air temperatures delay flower openings, resulting in "irregular" blooming and overlap of female and male stages among 'Hass' trees. Initial studies of avocado outcrossing were typically conducted in warm, dry environments, including Israel and inland California (Degani et al., 1989, 1990, 1997; Kobayashi et al., 2000; Vrecenar-Gadus and Ellstrand, 1985). Researchers have noted that coastal orchards, such as the one used in the current study, are more likely to experience the cool air temperatures that delay flower openings (Bekey, 1986; Lesley and Bringhurst, 1951). This could result in high rates of self-pollination among 'Hass' trees, thereby decreasing the role of outcrossing in final yield, which is consistent with the results of the current study. However, Kobayashi et al. (2000) used both inland and coastal California sites. A significant correlation $\left(r^{2}=0.50, P=0.03\right)$ between outcrossing and yield was only detected at one of the coastal sites (Kobayashi et al., 2000).

In the current research, it is likely that the high rate of outcrossing of a single tree $(\mathrm{F})$ was a result of its proximity $(6 \mathrm{~m})$ to a 'Bacon' tree. However, outcrossing rates of the remaining data trees were not related to distance to the nearest pollinizer, despite the closeness of data trees to pollinizer trees. Similarly, although outcrossing was detected during both study years among 'Hass' data trees that were up to $40 \mathrm{~m}$ from the nearest pollinizer tree, other data trees as close as $17 \mathrm{~m}$ had outcrossing rates of $0 \%$ in at least one year of the 2-year study (Table 4). Vrecenar-Gadus and Ellstrand (1985) identified fruit that were the product of outcrossing with 'Bacon' within a solid
California planting of 'Hass', with the nearest 'Bacon' tree located $80 \mathrm{~m}$ from the 'Hass' study trees. Many authors have reported that outcrossing rates decreased appreciably as distance from pollinizer trees increased (Degani et al., 1989, 1990, 1997; Kobayashi et al., 2000; Vrecenar-Gadus and Ellstrand, 1985). In California, Kobayashi et al. (2000) determined outcrossing rates for 'Hass' trees that were 1, 5, and 15 rows from potential pollinizer trees. Although the effect was not consistent across experimental sites, overall, there was a $23 \%$ decrease in the outcrossing rate as the distance between 'Hass' and pollinizer trees increased (Kobayashi et al., 2000). That higher outcrossing rates require close proximity between 'Hass' and pollinizer trees is likely due to the foraging habits of honeybees (Apis mellifera L.) within avocado orchards. The movement of honeybees to adjacent rows decreases hyperbolically (Ish-Am and Eisikowitch, 1998), suggesting that significant increases in the rate of outcrossing require high densities of bees and pollinizer trees. For example, if high outcrossing rates are only possible when each 'Hass' tree is adjacent to a pollinizer tree, as was determined for both years of this research, a minimum of $16 \%$ of trees in an orchard planted on the square must be pollinizer trees. The financial return of pollinizer cultivars in California is extremely low in comparison with 'Hass'. The price per kilogram of 'Hass' was at least three times greater than non-Hass cultivars during the 2000-01 season (California Avocado Commission, 2002). Therefore, the cost of interplanting pollinizer cultivars could far exceed the monetary benefits of any potential increases in 'Hass' yields that outcrossing might provide, especially during years when environmental conditions during bloom decrease the likelihood of outcrossing.

Sixty-five percent of outcrossed embryos were definitively identified as products of outcrossing with 'Bacon' based on the presence of the $Y$ allele (16 $Z Y$ and $8 X Y$ embryo genotypes; Table 2). As the $W$ allele was common to all potential pollinizer cultivars, the pollen parent of $35 \%$ of outcrossed embryos (seven $Z W$ and six $X W$ embryo genotypes; Table 4 ) could not be specifically determined. The $V$ allele, which was unique to 'Topa Topa', was not detected in any sampled embryos, possibly due to limited bloom overlap of the single 'Topa Topa' tree with 'Hass' trees (less than $65 \%$ and $34 \%$ during the on- and off-crop years, respectively) (Garner, 2004). The rogue 
tree ( $W W$ genotype) was always the most distant pollinizer in relation to the data trees (226 to $326 \mathrm{~m}$; Table 4). However, there were more 'Bacon' trees than any other pollinizer and for every 'Hass' data tree-including tree F, which accounted for the majority of detected outcrossing events - a 'Bacon' tree was the closest pollinizer. Furthermore, the bloom overlap between 'Hass' data trees and 'Bacon' was at least 80\% (Garner, 2004). These facts taken together, strongly suggest that the 'Bacon' trees were the most likely pollen parents of embryos possessing the $W$ allele and therefore, the most likely pollen parent of all fruit that were the product of outcrossing in the experiment described herein. The Bacon cultivar has previously been shown to outcross with 'Hass' in California orchards (Kobayashi et al., 2000; Vrecenar-Gadus and Ellstrand, 1985).

It is interesting to note that the ratio of $Y$ to $W$ alleles $(1.9: 1)$ is significantly different from that predicted by Mendelian segregation (1:1), even if 'Bacon' was the only pollen parent contributing to outcrossing. Recent work by Ashworth and Clegg (unpublished data) using the AVO.102 marker resulted in a $1.6: 1$ ratio of $Y$ to $W$ alleles among 106 'Zutano' $\mathrm{F}_{2}$ progeny. The ratios reported herein could be due to biased segregation ratios, although the limited sample size could also account for this result.

Previous studies have not reported the examination of or differences in outcrossing rates between on- and off-year crops or the effects, if any, on alternate bearing. In the research reported herein, outcrossing rates were not significantly different between on- and off-crop years and thus were not related to ABI.

This research demonstrated that high 'Hass' avocado yields are possible under California growing conditions, regardless of outcrossing rates. Alternate bearing also occurred, irrespective of outcrossing rates. This research also establishes the feasibility of molecular markers for further investigations of avocado outcrossing. However, the results of this research also add to a growing body of knowledge that suggests high rates of outcrossing throughout a California 'Hass' orchard can only be achieved with large and, therefore, expensive interplantings of pollinizer cultivars. Other factors influencing flower and fruit retention likely play a fundamental role in determining yield, and should, therefore, be investigated to develop strategies for increasing 'Hass' avocado yields.

\section{Literature Cited}

Arpaia, M.L., D. Stottlemyer, L.M. Bates, and E. Focht. 2005. The California cross pollination experiment: A progress report on the influence of pollinizer variety and proximity on 'Hass' yield. 29 Jan. 2007. <http://avocadosource.com/journals/ausnz/ausnz_2005/ arpaiamarylu2005d.pdf $>$.

Ashworth, V.E.T.M., M.C. Kobayashi, M. De La Cruz, and M.T. Clegg. 2004. Microsatellite markers in avocado (Persea americana Mill.): Development of dinucleotide and trinucleotide markers. Scientia Hort. 101:255-267.

Bekey, R. 1986. Pollination of avocado: Some new insights with special reference to the 'Hass' variety. California Avocado Soc. Yrbk. 70:91-97. Bower, J.P., C.J. Lovatt, J. Cutting, and M.M. Blanke. 1990. Interaction of plant growth regulator and carbohydrate in flowering and fruit set. Acta Hort. 275:425-434.
California Avocado Commission. 2002. Report: Pounds and dollars by variety, November 00-October 01. 20 Aug. 2003. <http://www. avocado.org/commission/2000_363.php?sd=commission>.

Cameron, S.H., R.T. Mueller, and A. Wallace. 1952. Nutrient composition and seasonal losses of avocado trees. California Avocado Soc. Yrbk. 37:201-209.

Davenport, T.L. 1982. Avocado growth and development. Proc. Florida State Hort. Soc. 95:92-96.

Degani, C., R. El-Batsri, and S. Gazit. 1997. Outcrossing rate, yield, and selective fruit abscission in 'Ettinger' and 'Ardith' avocado plots. J. Amer. Soc. Hort. Sci. 122:813-817.

Degani, C., A. Goldring, I. Adato, R. El-Batsri, and S. Gazit. 1990. Pollen parent effect on outcrossing rate, yield, and fruit characteristics of 'Fuerte' avocado. HortScience 25:471-473.

Degani, C., A. Goldring, and S. Gazit. 1989. Pollen parent effect on outcrossing rate in 'Hass' and 'Fuerte' avocado plots during fruit development. J. Amer. Soc. Hort. Sci. 114:106-111.

Degani, C., A. Goldring, S. Gazit, and U. Lavi. 1986. Genetic selection during the abscission of avocado fruitlets. HortScience 21:11871188 .

Demirkol, A. 2002. Phenological and pomological characteristics and yields of some avocado cultivars grown in Antalya ecological conditions (in Turkish). Anadolu 12:49-64.

Garner, L.G. 2004. Characterization and manipulation of flower and fruit abscission of 'Hass' avocado (Persea americana Mill.). Univ. California, Riverside, PhD Diss., Abstr. 31-30259.

Garner, L.C. and C.J. Lovatt. 2008. The relationship between flower and fruit abscission and alternate bearing of 'Hass' avocado. J. Amer. Soc. Hort. Sci. 133(1):3-10.

Inoue, H. and B. Takahashi. 1990. Studies on the bearing behavior and yield composition of the avocado tree (in Japanese). J. Jpn. Soc. Hort. Sci. 59:487-501.

Ish-Am, G. and D. Eisikowitch. 1998. Mobility of honey bees (Apidae, Apis mellifera L.) during foraging in avocado orchards. Apidologie (Celle) 29:209-219.

Kobayashi, M., J. Lin, J. Davis, L. Francis, and M.T. Clegg. 2000. Quantitative analysis of avocado outcrossing and yield in California using RAPD markers. Scientia Hort. 86:135-149.

Lahav, E. and D. Zamet. 1975. Flower, fruitlet and fruit abscission in avocado trees (in Hebrew). Alon Hanotea 29:556-562.

Lesley, J.W. and R.S. Bringhurst. 1951. Environmental conditions affecting pollination of avocados. California Avocado Soc. Yrbk. 36:169-173.

Loupassaki, M.H., M. Vasilakakis, and I.I. Androulakis. 1995. The time of flowering of avocado and the female and male opening of flowers in Crete. Adv. Hort. Sci. 9:37-42.

Neter, J.W., W. Wasserman, and M.H. Kutner. 1990. Applied linear statistical models. Irwin, Homewood, IL.

Slabbert, M.J. 1981. Flower and fruit drop. South African Avocado Growers' Assn. Yrbk. 4:89-91.

Stout, A.B. 1923. A study in cross-pollination of avocados in southern California. California Avocado Assn. Ann. Rpt. 7:29-45.

Vrecenar-Gadus, M. and N.C. Ellstrand. 1985. The effect of planting design on out-crossing rate and yield in the 'Hass' avocado. Scientia Hort. 27:215-221.

Whiley, A.W. and B. Schaffer. 1994. Avocado, p. 3-35. In: B. Schaffer and P.C. Anderson (eds.). Handbook of environmental physiology of fruit crops: Volume II. Sub-tropical and tropical crops. CRC Press, Boca Raton, FL.

Winslow, M.M. and J. Enderud. 1955. Flowering behavior and yields of some avocado varieties at Riverside. California Avocado Soc. Yrbk. 39:133-135. 